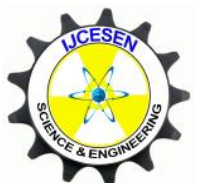

Copyright C IJCESEN
International Journal of Computational and

Experimental Science and ENgineering

(IJCESEN)

Vol. 6-No.1 (2020) pp. 35-41

http://dergipark.org.tr/en/pub/ijcesen

Research Article

\title{
Computer Aided Pressure Transient Analysis of a Layered Reservoir System with a Constant Pressure Boundary
}

\author{
Elohor D. AKPOBI ${ }^{1}$ and Erhuvwuvoke EBOJOH*² \\ ${ }^{1}$ University of Benin, Faculty of Engineering, Department of Petroleum Engineering, Benin City, Nigeria \\ ${ }^{2}$ University of Benin, Faculty of Engineering, Department of Production Engineering, Benin City, Nigeria \\ * Corresponding Author : voke.ebojoh@uniben.edu \\ ORCID: 0000-0001-5432-6020
}

\section{Article Info:}

DOI: $10.22399 /$ ijcesen.619912

Received : 13 September 2019

Accepted : 15 March 2020

\section{$\underline{\text { Keywords }}$}

Layered reservoir

Horizontal well

Object oriented programming

Dimensionless pressure

Dimensionless pressure derivative

\begin{abstract}
$\underline{\text { Abstract: }}$
A Layered reservoir system with a constant pressure bottom boundary has immense potential to produce oil and gas, using horizontal wells may further increase productivity because it offers a larger surface area for fluid withdrawal. Test analysis in this system is tedious, time consuming and interpretation may be confusing or erroneous. Hence an efficient algorithm is needed to generate accurate pressure response of the wells to facilitate quick and easy analysis and prediction. This paper presents an interactive computer program that computes the dimensionless pressure and dimensionless pressure derivatives of horizontal wells in a two layered reservoir system with a constant pressure boundary. Program's codes and structure of the reservoir model solution were written utilising the exponential integral solution, Gauss Laguerre and Gauss Lagrange numerical methods. The program has features that gave visual interpretation (graphical user interfaces (GUI)) as it computes pressure and derivative values when the interface between the layers is either permeable (crossflow reservoir) or impermeable (no crossflow reservoir). Examples illustrating its use in model identification and well test analysis of layered system with constant pressure boundary are also included in this work. Hence it will serve as a good learning tool because it is user friendly, fast and results have acceptable level of accuracy.
\end{abstract}

\section{Introduction}

The petroleum industry has witnessed a massive increase in software applications in recent times, though computers cannot replace human judgement, they have become indispensable to the petroleum engineer in the area of oil and gas prediction, understanding complex processes, planning maintenance and forecasting. Most software are problem or process specific (customised to solve unique challenges) while others are more general and available for public use $[1,2,3]$. The use of computer application in pressure transient analysis has numerous advantages over manual analysis. The benefits include increased productivity and improved quality of test and analysis in the shortest possible time
[4, 5, 6 and 7]. Layered reservoirs analysis are complicated, due to the existence of different layers with varying permeability, porosity and formation characteristics, pressure transient test analysis of these systems are difficult. Different mathematical methods employed to obtain solution to the flow equations for the layered models, include the Laplace transform, finite difference, modified Bessel function, linear regression analysis and the source function method [ 8, 9,10 and 11]. For these systems with complex configuration, robust computer programs are needed to ease analysis and interpretation. In this work the mathematical solutions to the reservoir models were presented. The models were developed using the Greens and Source function method to model the two layered reservoir subject to a 
bottom waterdrive using horizontal wells. An efficient and fast computer algorithm was developed and presented. This algorithm can compute fast and accurate values of pressure and pressure derivative of a two layered reservoir system. In addition a visual display of the solution for quick and easy interpretation of the results was provided. The program created a platform where different configurations of the reservoir and horizontal wells can be envisaged and evaluated. It has the capacity to compute the number of flow periods that will prevail for a particular set of well/reservoir parameters, crossflow coefficient, modification factor and total system permeability. Graphical representations of results were also provided. Typical numerical examples were used to test the performance of the program and highlight its application in well test analysis of layered system with constant pressure boundary

\section{Design of Software Model}

The two layered reservoir model with horizontal wells developed in [12] was used in this work. Relevant equations such as equations (9)-(19) were employed in the design of the software using programming technique of Visual Basic.Net [13].

\subsection{Dimensionless parameters}

For simplicity and easy comparison with other works, parameters were converted to their dimensionless form. Equation (1) was adopted to model dimensionless distances of the reservoir and the well. Effective dimensionless wellbore radius was modelled using equation (2) [14]

$$
\begin{aligned}
& i_{D}=\frac{2 i}{L} \sqrt{\frac{k}{k_{i}}} \\
& \mathrm{R}_{e D}=\frac{r_{w}}{L}\left(\sqrt{\frac{k}{k_{z}}}+\sqrt{\frac{k}{k_{y}}}\right)
\end{aligned}
$$

Dimensionless time and pressure and pressure drop were modelled using equation (3), (4) and (5) respectively [15]

$$
\begin{aligned}
\mathbf{t}_{\mathrm{Di}} & =\frac{\mathrm{Kt}}{\varphi \mu \mathrm{C}_{\mathrm{t}}\left(\frac{L}{2}\right)^{2}} \\
p_{D} & =\frac{2 \pi k h \Delta p}{q \mu}
\end{aligned}
$$

The pressure drop caused by production from a continuous source in a well is expressed as

$$
\Delta p(x, y, z, t)=\frac{1}{\phi C_{t}} \int_{0}^{t} q_{L} S(x, y, z, t) d t
$$

Where $\mathrm{s}(\mathrm{x}, \mathrm{y}, \mathrm{z}, \mathrm{t})$ represents the instantaneous source function (ISF) for the particular reservoir and well configuration.

\subsection{Layered system equations}

Source and Greens Function were selected to assemble each layer's dimensionless pressure $\left(\mathrm{P}_{\mathrm{Di}}\right)$ using the Newman's product rule]. Utilising the superposition principle the full $\mathrm{P}_{\mathrm{D}}$ for the well and reservoir system was evaluated as (6) and (7). Derivatives of the $P_{D}$ were computed using equation (8).

$P_{D 1}\left(X_{D}, Y_{D}, Z_{D}, \tau\right)=2 \pi h_{D} \int_{0}^{t_{D}} S\left(X_{D 1}, \tau\right) S\left(Y_{D 1}, \tau\right) \cdot S\left(Z_{D 1}, \tau\right) d \tau_{D}$

$P_{D i}=P_{a}+P_{b}+\ldots \ldots \ldots . P_{n}$

Where i represents the layer and $\mathrm{a}, \mathrm{b}$ and $\mathrm{n}$ the flow periods.

$$
P_{D}^{\prime}=\frac{\partial P_{D}}{\partial \operatorname{In} t_{D}}
$$

$\mathrm{P}_{\mathrm{D}}$ for early radial flow period common to both no crossflow and crossflow layered systems was represented by equation (9)

$$
P_{D}=\frac{\alpha}{8 L_{D}} \sqrt{\frac{K}{K_{y}}} E i\left(-\frac{r_{W D}^{2}}{4 \tau_{D}}\right)
$$

\subsubsection{No crosssflow layered system}

$\mathrm{P}_{\mathrm{D}}$ for intermediate and late time flow periods of layer one given in equations (10) and (11)
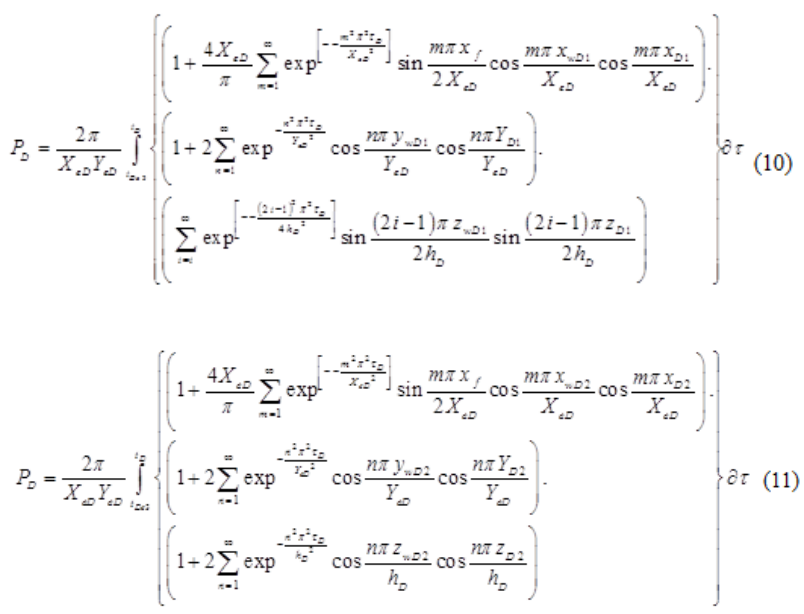


\subsubsection{Crossflow layered system}

Owing to the permeable interface in the crossflow layered reservoir system, the following additional parameters are required for proper modelling of the system.

Modification factor $\left(\mathrm{E}_{\mathrm{J}}\right)$

$$
E_{J}=\frac{W_{1}+W_{2}}{2 \pi\left(W_{1}^{2}+W_{2}^{2}\right)}
$$

$\mathrm{P}_{\mathrm{D}}$ for intermediate and late time flow periods in layer one are determined by equations (14) and (15)

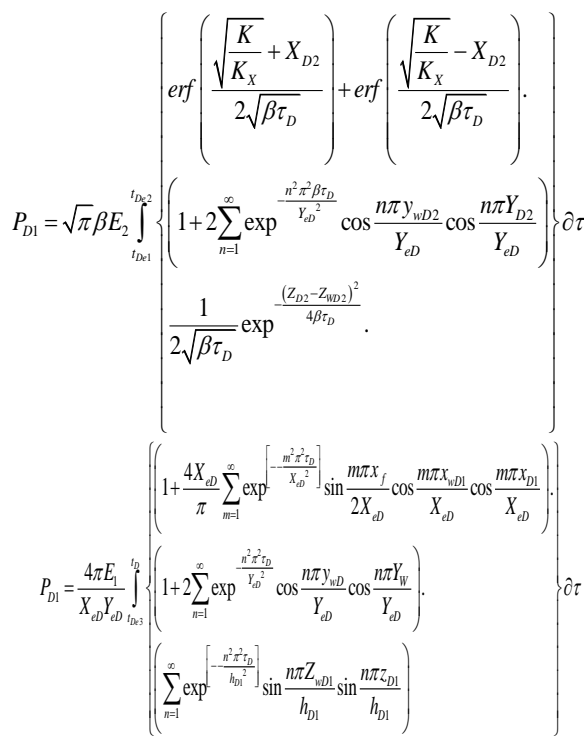

\subsection{Program description}

The program was designed and implemented with the aid of Visual Basic Programming language. This robust programming tool enables the equations involved in the layered mathematical models to be coded. The programming process involved three main steps.

\subsubsection{Input stage}

Several graphical user interfaces (GUI's) were designed with forms, labels, textboxes and command buttons. The user chooses the type of reservoir, then he inputs well, fluid and reservoir data(in S.I units ) necessary for the determination of the $\mathrm{P}_{\mathrm{D}}$.

\subsubsection{Analysis}

Where $\mathrm{W}_{1}$ and $\mathrm{W}_{2}$ represent $\mathrm{P}_{\mathrm{D}}$ of layer one and layer two of the system.

Total pay thickness $\left(\mathrm{h}_{\mathrm{Dt}}\right)$ for the system

$\mathrm{h}_{\mathrm{Dt}}=h_{D 1}+h_{D 2}$

Time normalisation factor or crossflow coefficient $(\beta)$

$\beta=\frac{\phi_{i} \mu_{i} C_{t i} L_{i}^{2} K_{i+1}}{\phi_{i+1} \mu_{i+1} C_{t i+1} L_{i+1}^{2} K_{i}}$

$\mathrm{P}_{\mathrm{D}}$ for intermediate and late time flow periods in layer two are determined by equations (17) and (18)

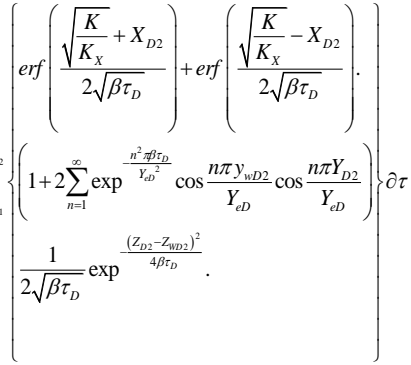

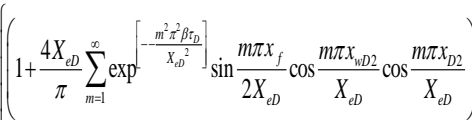

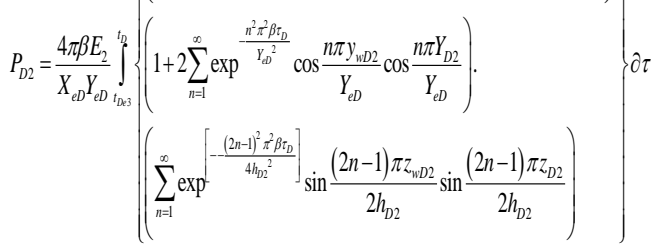

The parameters are converted to their dimensionless form and used in the computations. The model equations contained complex summation and integrals that can only be handled numerically. The pressure response for the early time flow period was computed using the exponential integral solution and Gauss Laguerre numerical method. The Gauss lagrange method was employed to determine the dimensionless pressure for the other flow periods $[16,17]$. Total $P_{D}$ for the system was assembled using the principle of superposition in time. The solution was processed speedily within seconds as a result of the robust codes used in programing the reservoir model. Flow chart of the program in figure 1 shows the steps involved in the analysis.

\subsubsection{Output stage}

Results for the computation of pressure and derivatives of the layered reservoir were displayed 
as numeric values in a data grid and also with an option of graphical representation on Cartesian scale plotting the $\log$ of dimensionless time $\left(\log t_{D}\right)$ against dimensionless pressure $\left(\log \mathrm{P}_{\mathrm{D}}\right)$

\section{Program Algorithm}

The following is the software's algorithm

\section{Start}

Select type of reservoir interface.

Option 1: No-crossflow layered reservoir

Option2: Crossflow layered reservoir

if option value $=1$ then if reservoir type is nocrossflow then

If desired parameter $=\mathrm{P}_{\mathrm{D}}$ Then Input known parameters $\mathbf{L}, \mathbf{h}, \mathbf{k}, \mathbf{z}_{\mathrm{w}}, \mathbf{r}_{\mathrm{w}}, \boldsymbol{\phi}, \boldsymbol{\mu}$

Compute flow periods $t_{\mathrm{DE} 1}, t_{\mathrm{DE} 2}, t_{\mathrm{DE} 3}, t_{\mathrm{D} 4}$. If dimensionless time $t_{D}<$ first flow period $T_{D E 1}$ Then Infinite acting flow period, Exponential integral Equation

Compute $\mathrm{P}_{\mathrm{D} 1}$ using the Laguerre quadrature End If Else If $t_{D E 3}>$ third flow period $t_{D E 3}$ Then Compute $\mathrm{P}_{\mathrm{DE} 3}$ using Legendre quadrature

$\mathrm{P}_{\mathrm{D}}=\mathrm{P}_{\mathrm{D} 1}+\mathrm{P}_{\mathrm{D} 2}+\mathrm{P}_{\mathrm{D} 3}+\ldots .$. End If. If option's value's $=2$

\section{Then}

If reservoir is crossflow systems Then Input known values of $\mathrm{L}, \mathrm{r}_{\mathrm{W}}, \mathrm{h}, \mathrm{z}_{\mathrm{w}}, \mathrm{k}_{\mathrm{y}}, \mathrm{k}_{\mathrm{x}}, \mathrm{k}_{\mathrm{z}}$

Compute BTA, $\mathrm{H}_{\mathrm{DT}}$, K, E

Compute flow periods $t_{\mathrm{DE} 1}, \mathrm{t}_{\mathrm{DE} 2,} \mathrm{t}_{\mathrm{DE} 3}, \mathrm{t}_{\mathrm{D} 4}$.

Compute $\mathrm{P}_{\mathrm{D} 1}, \mathrm{P}_{\mathrm{D} 2}, \mathrm{P}_{\mathrm{D} 3}, \mathrm{P}_{\mathrm{D} 4}$ using same method as no crossflow reservoir

End IF Compute Pressure derivative using differentiation

Else If $t_{D}>$ second flow period $T_{D E 2}$ Then Compute $\mathrm{P}_{\mathrm{D} 2}$ using Lagendre quadrature

Plot graph

End

\section{Results and Discussion}

Numeric examples (Tables 1 and 2) were employed to demonstrate the relevance and robustness of the software. The following well/fluid properties were assumed constant for both (crossflow and no crossflow) reservoir system. Wellbore radius $\left(r_{\mathrm{w}}\right)=$ $0.375 \mathrm{ft}$, total compressibility $\left(\mathrm{C}_{\mathrm{t}}\right)=3.0 \mathrm{E}-6 \mathrm{psi}^{-1}$, Porosity $(\varphi)=1 \%$, Viscosity $(\mu)=1 \mathrm{Cp}$. Using the data from table one, values of pressure and derivative of horizontal wells situated in each layer were generated. The results(increasing pressure and derivative values with time)for layer one indicates that the top layer(layer 2) behaves like a reservoir with no flow boundaries having no communication with the upper layerbecause the interface is sealed

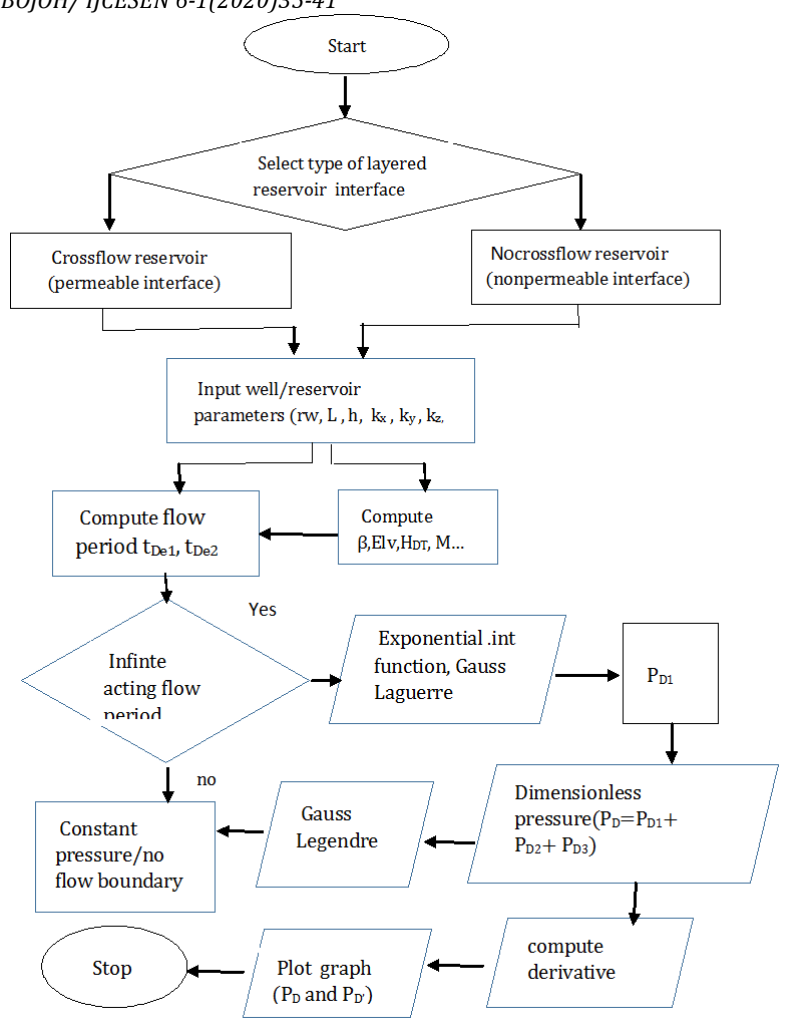

Figure 1: Flowchart for the computer program.

(nocrossflow).Pressure and derivative response from layer one depicts the trend of a reservoir with a bottom waterdrive (constant pressure boundary) as pressure values increase and becomes constant while the derivative display initial constant values at early time with a collapse to zero at late time. Figures (2)-(5) clearly depicts the results for no crossflow system. For crossflow system, same procedure for computing pressure and derivative was adopted. The program computed the flow periods that may occur, crossflow coefficients, mo dification factor, total pay thickness and total permeability of the system. So as to reduce congestion on the crossflow

Table. 1 Showing well/reservoir data for No-Crossflow reservoir system.

\begin{tabular}{|c|c|}
\hline Parameter & Value \\
\hline $\mathrm{L}, \mathrm{ft}$ & 1000 \\
\hline $\mathrm{h}, \mathrm{ft}$ & 200 \\
\hline $\mathrm{Z}_{\mathrm{w}}, \mathrm{ft}$ & 100 \\
$\mathrm{X}_{\mathrm{e}, \mathrm{ft}}$ & 6000 \\
\hline $\mathrm{Y}_{\mathrm{e}, \mathrm{ft}}$ & 6000 \\
\hline $\mathrm{Elv}, \mathrm{ft}$ & 20 \\
\hline $\mathrm{K}_{\mathrm{i}}, \mathrm{md}$ & $1: 1: 1$ \\
\hline
\end{tabular}


Table. 2 Showing well/reservoir data for Crossflow reservoir system.

\begin{tabular}{|c|c|c|}
\hline $\begin{array}{c}\text { Parameter } \\
\mathrm{L}, \mathrm{ft}\end{array}$ & $\begin{array}{c}\text { Layer 1 } \\
1000\end{array}$ & $\begin{array}{c}\text { Layer } 2 \\
1000\end{array}$ \\
\hline $\mathrm{h}, \mathrm{ft}$ & 100 & 100 \\
\hline $\mathrm{Z}_{\mathrm{w}}, \mathrm{ft}$ & 50 & 50 \\
\hline $\mathrm{X}_{\mathrm{e}}, \mathrm{ft}$ & 16000 & 16000 \\
\hline $\mathrm{Y}_{\mathrm{e}} \mathrm{ft}$ & 10000 & 10000 \\
\hline $\mathrm{Elv}, \mathrm{ft}$ & 10 & 10 \\
\hline $\mathrm{K}_{\mathrm{i}}, \mathrm{md}$ & $1: 1: 1$ & $10: 10: 10$ \\
\hline
\end{tabular}

reservoir form. These results can be viewed from the immediate window. Results were also displayed in a datagrid shown in figures (6)-(9). Layer one and two display similar trend for pressure and derivative. Similarity in behavoir can be traced to the permeable interface, There is communication(crossflow) between the layers, pressure values increased with time and stabilized at late time while derivatve was initially constant but collapsed to zero at latetimes. Both layers behave like reservoirs that have a constant pressure boundary. For proper visual appreciation and interpretation of results cartesian plots of the results were provided. The usefulness and effectiveness of the computer programs can be seen clearly. All aspect of pressure transient test analysis: data preparation, model identification, parameter calculation, and model validation and presentation of results have benefited because of the use of computer[18, 19]

\section{Conclusion}

This work has presented models for a two layered reservoir with horizontal wells, also formulated and presented a computer program to generate dimensionless pressure and derivative values of the reservoir system with a bottom water drive. User friendly GUI's were designed for input of data and output of results. From the results shown in figure 2-5 it was observed that the pressure and derivative response of no crossflow reservoir system was higher, layer 1 displayed the behaviour of a bottom water drive reservoir while layer 2 showed the characteristics of a bounded reservoir whose lateral boundaries are infinite. Figure 6-9 showed screenshots of GUI's for the crossflow reservoir. Similarity in flow behaviour for both layers was observed, at early time pressure values increased and became constant at late times while derivative values became constant and collapsed to zero. This response is typical of that of reservoir with a

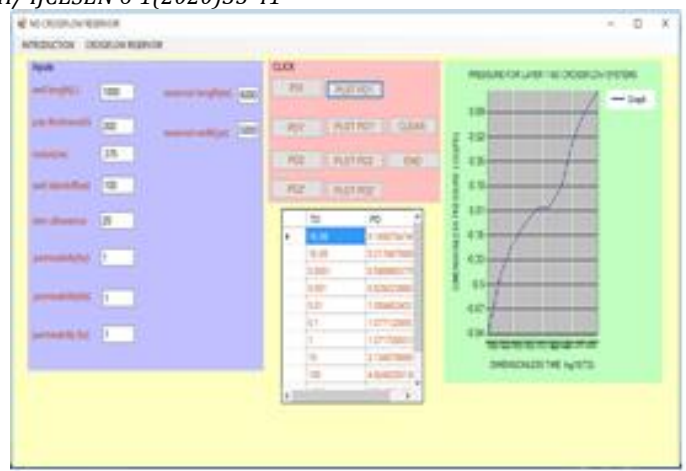

Figure 2: Screenshot of result for (no crossflow reservoir) layer 1 dimensionless pressure computations and graph plot

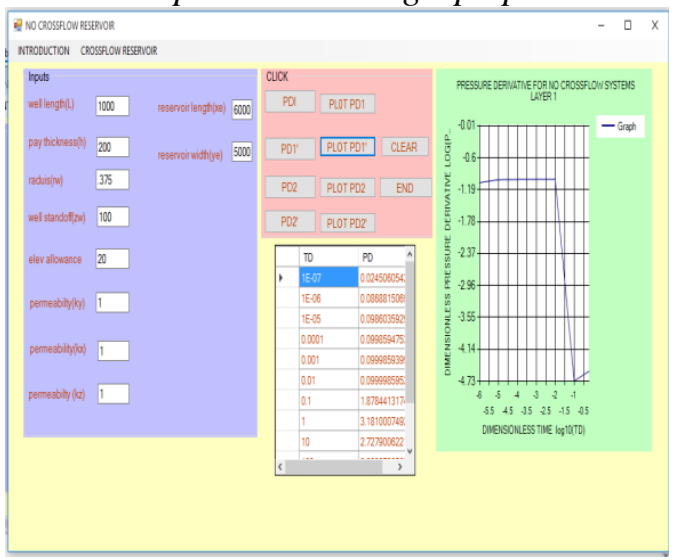

Figure 3: Screenshot of result for (no flow reservoir) layer 1 dimensionless pressure derivative and graph plot

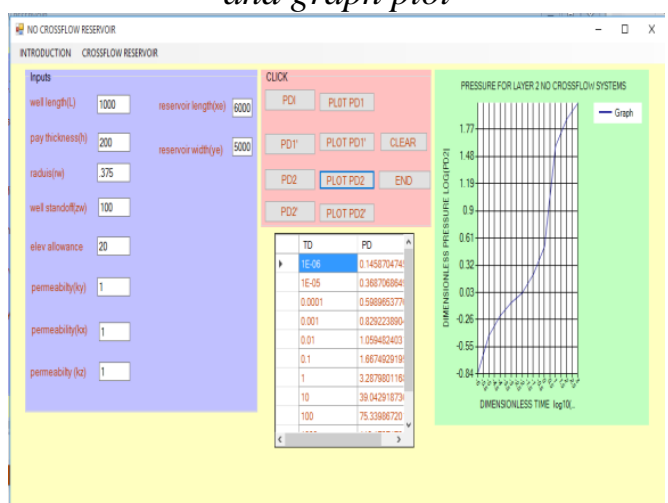

Figure 4: Screenshot of result for (no crossflow reservoir) layer 2 dimensionless pressure computations and graph plot.

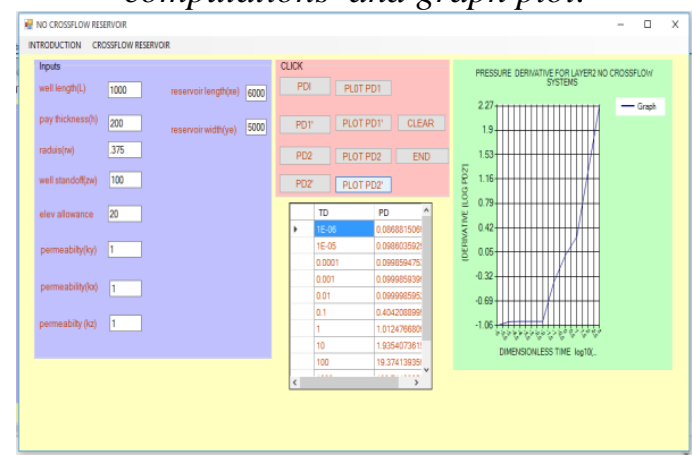

Figure 5: Screenshot of result for (no crossflow reservoir) layer 2 dimensionless pressure derivative and graph plot 


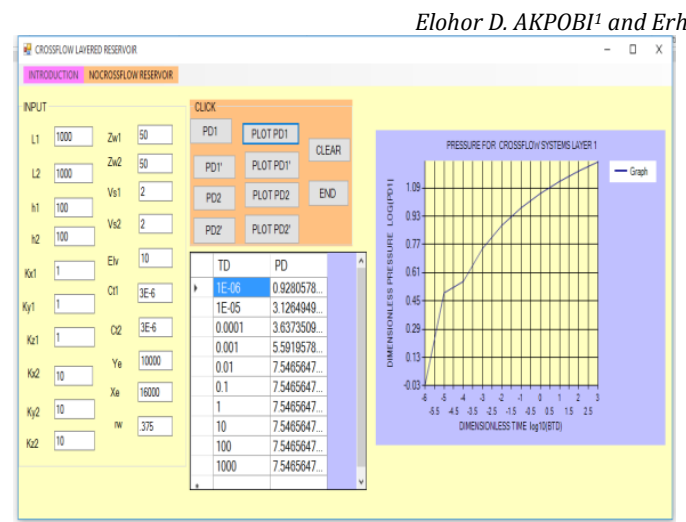

Figure 6: Screenshot of results for (Crossflow reservoir) layer 1 dimensionless pressure computations and graph plot.

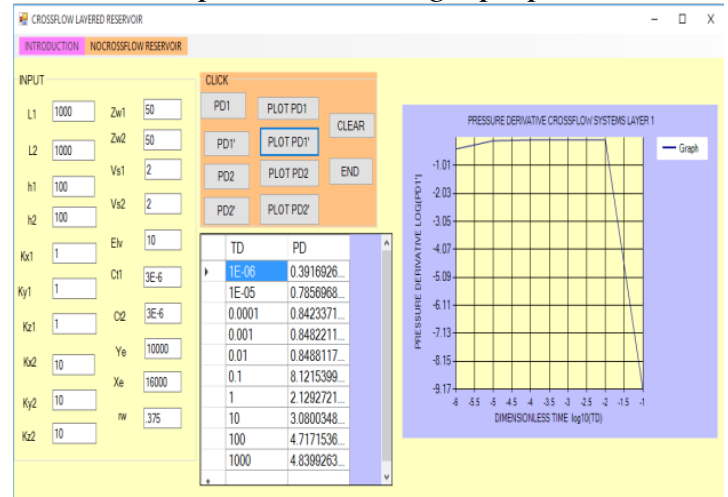

Figure 7: Screenshot of result for (Crossflow reservoir) layer 1 dimensionless pressure derivative and graph plot

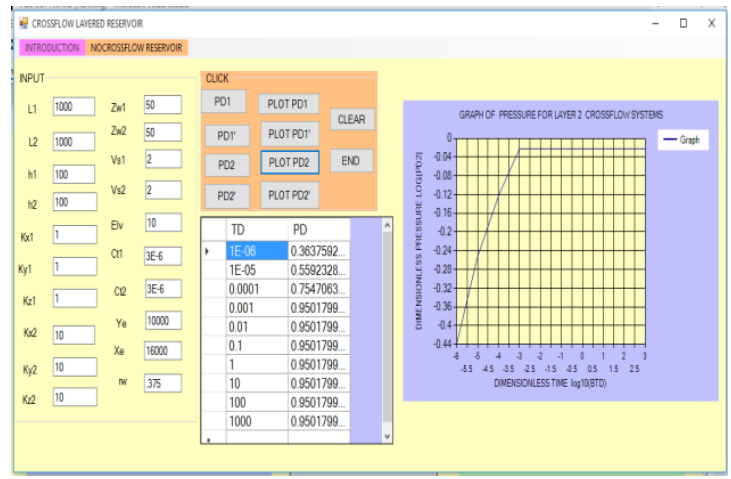

Figure 8: Screenshot of results for (Crossflow reservoir) layer 2 dimensionless pressure computations and graph plot

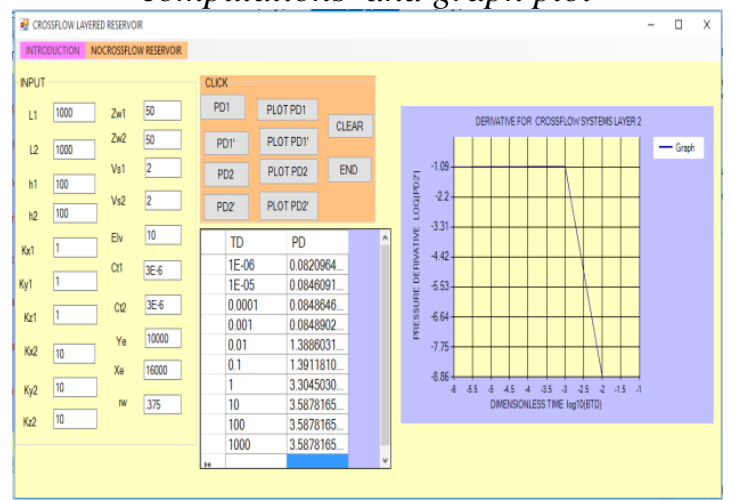

Figure 9: Screenshot of results for Crossflow reservoir layer 2 dimensionless pressure derivative and graph plot. constant pressure boundary with the more permeable layer (layer 2) having a lower pressure and derivative response. The graph of the results further highlights the capability of the computer program in model identification and reservoir characterization. Results from this study will improve the quality of test analysis of layered reservoir system with bottom water drive using horizontal wells, especially in the areas of drawdown, build up and interference test. It will also serve as an effective learning tool because it's easy and fast and results have acceptable level of accuracy.

\section{References}

[1] Ehlig-Economides, C.A,. Joseph J.A., Ambrose, R.W. and Norwood, C "A Modern Approach to reservoir test Interpretation" Society of Petroleum Engineers (SPE)paper $19814 \quad 64^{\mathrm{TH}}$ Annual technical conference and Exhibitions San Antonio Texas

October 8-11 1989.

[2] Nashawi, I.S., Al Anzi, E.H. and Hashew, Y.S. "A Depletion Strategy for an Active bottom Water Drive Reservoir Using Analytical and Numerical Models -Field Case Study" Journal of Heat Transfer Transactions of American society of mechanical enginners(ASME), Vol. 131 / 10100812, 2009.

[3] Majid, E. N., Abdolnabi, H. and Ali, Z."Challenges in Well Testing Data from Multi-Layered Reservoirs; a Field Case" International Journal of Science and Emerging Technology Vol. 4(6) pp. 208-216, 2012.

[4] McVay, D.A,. Hill, N,C., Lancaster, D.G and Holditch, S.A. "Interactive well test Analysis using microcomputers" Journal of Petroleum Technology (JPT) September, pp.12271231,1988.

[5] Kodhelaj, N and Bozgo, S. "Role of Well Testing and Information in Petroleum Industry-Testing in Multi-layeredReservoir International Journal of Engineering Science and Computing, July pp. 1647-1652, 2016.

[6] Gringarten, A.C. "Computer-Aided Well Test Analysis" Society of Petroleum Engineers International Meeting on Petroleum Engineering Beijing China, March 17-20, pp. 373-392, 1986.

[7] Horne, R. N. "Advances in Computer-Aided Well test Interpretation" Society of Petroleum Engineers Journal of Petroleum Technology, Vol.46, Number 7 , 599- 6051994.

pp.

[8] Bourdet, D. "Pressure Behaviour of Layered Reservoirs with Crossflow" Society of Petroleum Engineers California Regional Meeting Bakersfield, California, March 27- 29, pp. 405411, 1985.

[9] Abbass, E. and Lin Song, C. "Computer Application on Well Test Mathematical Model 
Computation of Homogenous and MultipleBounded Reservoirs", International Journal of Research and Reviews in Applied Studies Vol.11, Number1, April pp. 41-52, 2012.

[10] Kuchuk, F.J. and Tarek H. "Pressure Behavior of Horizontal Wells in MultilayerReservoirs with Crossflow," Society of Petroleum Engineer (SPE) Formation

Evaluation, March, pp.54 -64, 1996.

[11] Erhunmwun, I. D. and Akpobi, J.A. Analysis of Pressure Variation of fluid in an Infinite Acting Reservoir. Nigerian Journal of Technology (NIJOTECH), Vol 36, No.1 January, pp.80-86, 2017

[12] Akpobi, E.D., Adewole, E.S. and Olafuyi, O. A. "Model for Layered Reservoir Subject to a Bottom Water Drive Using Horizontal Wells" Journal of the Nigerian Association of Mathematical Physics Vol.35 pp.311- 322, 2016.

[13] Kaur, K. Microsoft Visual Basic.Net. Professional Projects, Premier press pp. 86-122, 2002.

[14] Gringarten, A.C. and Ramey, H.J. "The Use of Source and Green's Function in Solving Unsteady Flow Problems in Reservoirs" Society of Petroleum Engineers Journal Vol:13, Pages:285-296, ISSN 0197-7520, 1973.

[15] Adewole E.S. "Instantaneous Source Function of a Permeable Interface", Journal of the Nigerian Association of Mathematical Physics Vol.4, pp.189-196, 2009

[16] Malekzadeh, D. "Interference Testing of horizontal wells" Ph.d Dissertation University of Oaklahoma, Oaklahoma, United States of America, 1991.

[17] Adewole, E. S. "The Use of Gauss Laguerre and Gauss Legendre Quadrature in Solving Problems Involving Oil Flow In Horizontal Wells " Journal of the Nigerian Association of Mathematical Physics Vol. 34, Number 2B Sept, pp.380 - 386, 2007.

[18] Okafor, H.E., Mohammad, J. and Farshid, A. Incorporating Oil and Gas Softwares into Petroleum Engineering EducationCurriculum"Engineering Science and Technology Journal vol.3 No.1, pp. 49-56, 2013.

[19] Buhidma, I.M. and Chu, W.C. "The Use of Computer in Pressure Transient Analysis. Society of Petroleum Engineers (SPE) Annual Technical Conference and Exhibition, Washington, D.C., October 4-7 pp.723- 734, 1992.

\section{Nomenclature}

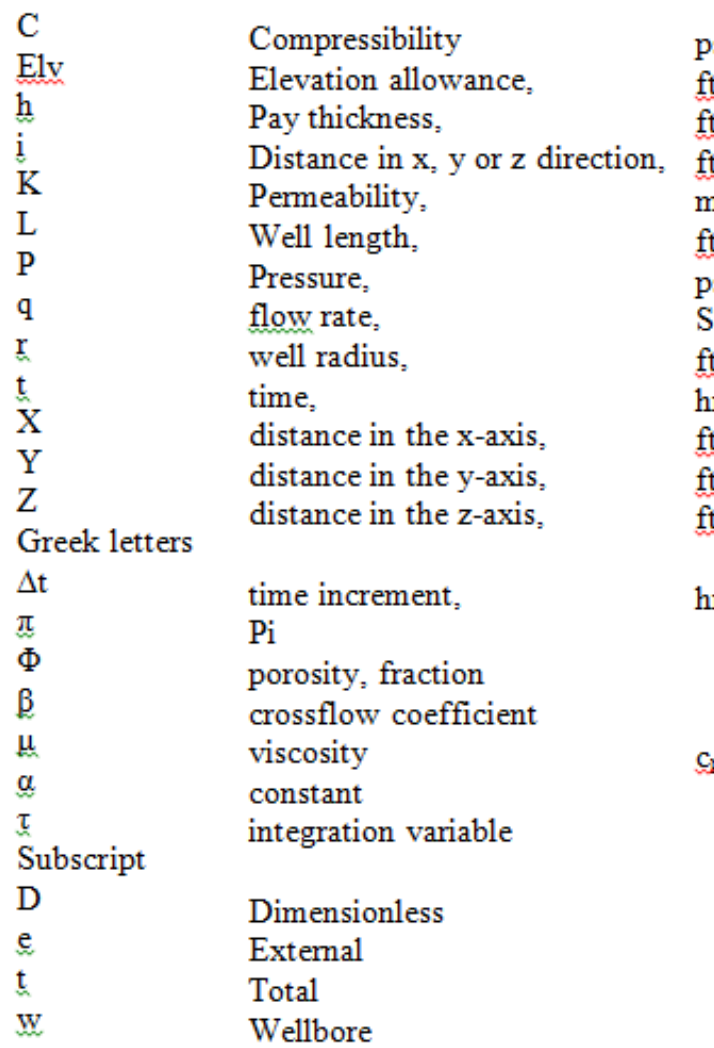

